\title{
Empreende - Ensinando a Gestão Empreendedora de Negócios
}

\author{
"Empreende" - Teaching Business Entrepreneurship \\ "Empreende" - La Enseñanza de la Educación Emprendedora
}

Recebido: 22/09/2021 | Revisado: 30/09/2021 | Aceito: 30/09/2021 | Publicado: 03/10/2021

Joelias Silva Pinto Júnior
ORCID: https://orcid.org/0000-0001-6810-5878
Instituto Federal de Educação, Ciência e Tecnologia de Mato Grosso, Brasil
E-mail: joelias.junior@ifmt.edu.br
Anderson Ricardo Silvestro
ORCID: https://orcid.org/0000-0002-7101-2522
E-mail: ricardo.silvestro@ifmt.edu.br
Instituto Federal de Educação, Ciência e Tecnologia de Mato Grosso, Brasil
Claudineia Gonçalves de Arruda
ORCID: https://orcid.org/0000-0001-7621-5321
Instituto Federal de Educação, Ciência e Tecnologia de Mato Grosso, Brasil
E-mail: claudineia.arruda@ bag.ifmt.edu.br
Antonio Vinicius Fernandes Nascimento
ORCID: https://orcid.org/0000-0001-8422-0200
E-mail: antoniovinicius012@gmail.com

\section{Resumo}

No Brasil, há uma realidade preocupante em que até $80 \%$ das empresas não conseguem se manter e fecham no primeiro ano de funcionamento. Este problema muitas vezes se deve ao despreparo de empresários. Dentre as principais causas, podemos citar algumas que poderiam ser evitadas como: falta de estudo de mercado, ausência de planejamento, desconhecimento de técnicas de marketing e gestão, não conhecimento do público-alvo, entre outros. Este artigo relata um projeto de extensão desenvolvido no Instituto Federal de Mato Grosso que identificou e selecionou micro e pequenos empreendedores que estavam com seus negócios em zona de vulnerabilidade (correndo risco de fechar) ou empreendedores informais com potencial para se formalizar e crescer. Neste projeto, foi fornecida capacitação em administração empreendedora para estes empreendedores, por meio de um curso Formação Inicial (FI) e, orientação e mentoria durante e imediatamente após a finalização do curso, para que possam gerenciar seus negócios com os conhecimentos apreendidos. A capacitação e as orientações e mentorias contribuíram para auxiliá-los a atuar no diagnóstico e solução de suas vulnerabilidades.

Palavras-chave: Empreendimento; Zona de vulnerabilidade; Capacitação; Empreendedorismo.

\begin{abstract}
In Brazil up to $80 \%$ of companies are unable to maintain themselves, so they close in the first year of operation. Often, this problem is due to a lack of preparation of entrepreneurs. Among the main causes, we can mention some that could be avoided, such as: lack of market research, lack of planning, lack of marketing and management techniques, lack of knowledge of the target audience, among others. This paper reports an extension project developed at the Federal Institute of Mato Grosso that identified and selected micro and small entrepreneurs who had their businesses in a vulnerable zone (at risk of closing) or informal entrepreneurs with the potential to formalize and grow. In this project, training in entrepreneurial administration was provided to these entrepreneurs, through an Initial Formation (IF) course, and guidance and mentoring during and immediately after completion of the course, so that they can manage their businesses with the knowledge learned. The training and guidance and mentoring helped them to work in the diagnosis and solution of their vulnerabilities.
\end{abstract}

Keywords: Enterprise; Vulnerability zone; Training; Entrepreneurship.

\section{Resumen}

En Brasil, existe una realidad preocupante en la que hasta el $80 \%$ de las empresas no pueden mantenerse. Así, cierran en el primer año de operación. Este problema se debe a menudo a la falta de preparación de los empresarios. Entre las principales causas, podemos mencionar algunas que podrían evitarse, como: falta de investigación de mercado, falta de planificación, falta de técnicas de marketing y gestión, desconocimiento del público objetivo, entre otras. Este artículo reporta un proyecto de extensión desarrollado en el Instituto Federal de Mato Grosso que identificó y seleccionó a micro y pequeños emprendedores que tenían sus negocios en una zona vulnerable o emprendedores informales con potencial para formalizarse y crecer. En este proyecto, se brindó capacitación en administración emprendedora a estos emprendedores, a través de un curso de Formación Inicial (FI), y orientación y mentoría durante e inmediatamente 
después de la finalización del curso, para que puedan manejar sus negocios con los conocimientos aprendidos. La formación, la orientación y la tutoría les ayudaron a trabajar en el diagnóstico y solución de sus vulnerabilidades. Palabras clave: Empresa; Zona de vulnerabilidad; Capacitación; Emprendimiento.

\section{Introdução}

Muitos empreendedores informais/individuais ou de micro ou pequeno porte iniciam seus empreendimentos com muita vontade, boas ideias, força de trabalho, mas de maneira empírica, sem buscar capacitação e os devidos conhecimentos técnicos. Por isso, pelo menos um terço das empresas no Brasil fecham antes de 2 anos de funcionamento (Exame, 2019) e (Rede Jornal Contábil, 2019). Se focarmos nas micro e pequenas empresas, pode chegar até a $80 \%$ a quantidade que fecham já no primeiro ano de funcionamento (Negócios Digitais na Prática, 2019).

Em experiências com outros projetos de extensão e pesquisa que envolviam empreendedores, fornecedores de produtos e prestadores de serviços em Barra do Garças, local em que ocorreu esta pesquisa, foi possível diversas vezes verificar esse despreparo na gestão de seus negócios. Era possível perceber a falta de noções básicas de administração e contabilidade, a ausência de investimento em marketing ou um investimento ineficaz, não demonstravam conhecer sistemas de gerenciamento de negócio ou não se sentiam capacitados a utilizar, entre outros problemas.

Verificando estas carências, iniciamos conversas informais com estes profissionais, destacando os pontos de vulnerabilidade que percebemos. Interrogando-os se tinham consciência destes, a maioria alegava não ter percebido e acrescentavam que sentiam falta de capacitação.

Segundo Pinto Júnior (2021) estabelecer um plano de capacitação e um plano de ação são formas eficazes de superar vulnerabilidades e auxiliar empreendimentos a passar por problemas empresariais.

Assim nasceu o projeto Empreende, que visou oferecer capacitação empreendedora a empreendedores formais ou informais, em zona de vulnerabilidade, da região de Barra do Garças, Pontal do Araguaia/MT e Aragarças/GO, por meio de capacitações, consultorias, assessorias e outras ferramentas de auxílio à modelagem e estruturação de negócios.

O projeto se postulou de grande importância para a consolidação e formação de negócios nos municípios da região de Barra do Garças/MT, Pontal do Araguaia/MT e Aragarças/GO. A consolidação destes negócios, bem como sua possível expansão, gera renda e contribui não só para o sustento de seus proprietários como de possíveis contratados futuros e como também de seus beneficiários indiretos.

\section{Fundamentação Teórica}

Para elaboração das capacitações ministradas neste projeto, bem como para as etapas de tutoria e mentoria foram usadas as definições mais recentes e amplas concernentes ao empreendedorismo e também os principais referenciais teóricos da área.

Em (IFMT, 2019) há um material sucinto, claro, explicativo e com linguagem acessível, voltado para o estudante empreendedor. Cada aluno recebeu uma cópia digital deste livro, por acreditarmos ter uma linguagem mais acessível e servir como base para o assunto, de modo a possibilitar que compreendam outros materiais.

Este livro, de autoria da Ativa Incubadora de Empresas, sediada na Pró-reitoria de Extensão do IFMT, define que "o empreendedorismo pode ser compreendido como a arte de fazer acontecer com criatividade e motivação", mas também destaca que para um empreendimento ter sucesso é necessário tecnologia, talentos, finanças, espaço físico/ infraestrutura e mercado.

Podemos partir deste conceito mais amplo para em seguida entender com mais detalhes, definições como dos teóricos Chiavenato (2015 e 2016) e Dornelas (2015 e 2016). Eles definem os aspectos do empreendedor como aquele que tem iniciativa para criar um novo negócio com paixão pelo que faz, que utiliza os recursos disponíveis de forma criativa, gerando transformação onde vive e que aceita assumir os riscos e possibilidades de fracassar. 
Assim, todo o curso foi estruturado, partindo de tópicos com uma abordagem de forma abrangente, chegando às particularidades ou especificidades de cada assunto, de acordo com a necessidade e viabilidade para o público-alvo.

Também foram utilizados como referencial bibliográfico manuais de empreendedorismo e inovação como as referências (Torres, 2014), (Mendes, 2015) e (Bernardi, 2012), por acreditarmos que o formato assistivo adotado nestes materiais facilita a compreensão dos alunos e a replicação do conhecimento apreendido.

A análise SWOT também foi uma técnica utilizada e enfatizada no trabalho com estes empreendimentos. A sigla, que em inglês significa Strengths, Weaknesses, Opportunities e Threats, traduz-se para Forças, Fraquezas, Oportunidades e Ameaças. Autores como Costa Júnior et al. (2021) e Helms e Nixon (2010) orientam sobre a utilidade de se embasar na SWOT tomada de decisão em relação a situações complexas de forma que se possa obter melhorias em um empreendimento.

Paralelamente aos diagnósticos técnicos dos empreendimentos, enfatizamos também a importância dos empreendedores estabelecerem os estudos nos tópicos de competências empreendedoras oferecidas. Isto porque este pacote forma o que autores como Estival et al. (2021) denominam de educação empreendedora. Outros autores, como Cope (2003) e Krugüer, Büger e Minello (2019), também colaboram explicando que neste conceito a educação empreendedora é aquela capaz de gerar valores econômicos ao negócio, deixando claro a transferência do conhecimento para resultados. Todos os livros digitais gratuitos/livres trabalhados no curso foram enviados aos alunos, para que pudessem ter material de apoio. As aulas priorizaram a utilização de materiais impressos ou digitais produzidos por professores que atuaram no curso.

$\mathrm{Na}$ realização do curso foi priorizado o uso de metodologias já reconhecidas por facilitar e potencializar o aprendizado prático de conteúdos, como: Estudos de Caso, Aula Prática, Simulados, Aprendizagem entre Pares ou Times, Galeria de Ideias, Espaço Aberto, entre outros.

\section{Metodologia}

Após aprovado este projeto, com o auxílio do Núcleo Incubador do Campus Barra do Garças, vinculado à Ativa Incubadora de Empresas do IFMT, foi realizado o processo de pré-incubação.

Neste momento foi desenvolvido um Curso FI em Competências Empreendedoras, oferecido presencialmente no IFMT Campus Barra do Garças. O objetivo deste curso foi capacitar 20 empreendedores entre pequenos, micro ou individual de forma prática, em gestão empreendedora de negócios, direcionado a realidade de seus negócios.

Possui carga de 57 h, divididas nos seguintes módulos:

- Empreendedorismo e Inovação (12 h);

- Gestão Financeira e Tributária (9 h);

- $\quad$ Apresentação Pessoal (3 h);

- $\quad$ Marketing para o Empreendedor $(6 \mathrm{~h})$;

- Ferramentas e Sistemas para Gestão de Negócios (9 h);

- $\quad$ Análise de casos reais (18 h).

O coordenador extensionista e seus colaboradores, tendo conhecimento dos negócios de cada um dos alunos, realizaram análises para verificar as vulnerabilidades e/ou pontos de melhoria em cada empreendimento. Em seguida, foram oferecidas, pelos professores especialistas, reuniões de orientação, para cada um destes alunos.

Das Mentoria e Assistência Técnica, cada empreendedor poderá solicitar agendamento de um horário para levar dúvidas pontuais a algum dos mentores disponíveis no Núcleo Incubador do Campus. Por exemplo, se um aluno está em dúvida como 
fazer o cálculo de retorno do investimento (ROI) de um investimento que pretende fazer, este poderá solicitar horário de mentoria com um professor de contabilidade.

É importante destacar que as ementas do curso FI de Competências Empreendedoras contemplam todos os tópicos que a Ativa Incubadora do IFMT orienta como obrigatórios de serem trabalhados no período de pré-incubação, sendo eles: Validação de Negócios, Modelagem de Negócios com Canvas, Prototipagem de Produtos e Serviços e Apresentação de Negócios com a técnica Pitch.

Além da capacitação ministrada, também foi oferecido apoio aos empreendimentos por meio de consultorias, assessorias e assistência técnica, de forma presencial. Ainda, foram convidados os empreendimentos pré-incubados a participar dos cursos, palestras e oficinas que o Núcleo Incubador do Campus promoveu ao longo do ano.

\section{Resultados e Discussão}

Visando o bom andamento do trabalho, o coordenador realizou as avaliações de conformidade regulares, verificando se os prazos e objetivos estavam em concordância, dentro do previsto no cronograma e objetivos do projeto. Assim, em caso de divergências em relação aos planejamentos, havia tempo hábil para rever e tomar as ações de correção necessárias.

Durante toda execução dos trabalhos, o coordenador extensionista e o aluno bolsista foram responsáveis por monitorar, acompanhar e fornecer o devido suporte às atividades previstas no cronograma de execução.

Foi de responsabilidade do aluno bolsista auxiliar o coordenador na preparação dos materiais, no atendimento aos demais professores do projeto, na elaboração de formulários e modelos, na formatação e estruturação do curso FI, na verificação de frequência dos alunos, no agendamento de atendimento dos alunos, dentre outras atividades.

Aos alunos do projeto foram passados os contatos do coordenador do projeto e esclarecido que eles poderiam entrar em contato a qualquer tempo em caso de problemas na permanência do projeto, dúvidas ou sugestões para a melhoria do mesmo.

Além disso, foi de responsabilidade de todos os membros do projeto o registro fotográfico regular das atividades realizadas no projeto. O coordenador do projeto, no início, orientou a todos sobre os critérios de qualidade das fotos em termos de resolução, foco e luminosidade. Todos enviaram as fotos ao aluno bolsista, que ficou responsável por selecionar as melhores, fazer correções, se necessárias e submeter mensalmente ao projeto no SUAP.

Ao professor coordenador, este ficou responsável por verificar semanalmente a regularidade de frequência do aluno bolsista e submeter, mensalmente, a lista de frequência.

\section{Conclusão}

Este projeto, de forma precípua, se conectou com o ensino e a pesquisa. Com o ensino, pois levou o conhecimento à empresa incubada por meio das consultorias, tutoriais e assistências técnicas realizadas.

Já com a pesquisa, é possível elencarmos as seguintes ligações: Os professores e alunos colaboradores do projeto desenvolveram atividades de pesquisa para elaboração do curso, das aulas e também para consultoria aos alunos. Os empreendedores pré-incubados foram instigados a, a partir de problemas identificados em seu negócio, pesquisar por conta própria conceitos complementares e aplicações daqueles conceitos, de forma a construir um perfil investigativo e emancipatório.

Com a execução deste trabalho foi possível atender 19 empreendedores, já que um não pode concluir. Eles se beneficiaram de um curso de Competências Empreendedoras e também de consultorias e mentorias em áreas específicas das quais seus empreendimentos encontravam vulnerabilidade. Assim, ao final os empreendimentos finalizaram com diversas vulnerabilidades sanadas, empreendimentos mais estáveis e conhecimento sobre empreendedorismo mais sólido. 
Este trabalho previa a finalização do mesmo com um evento para confraternização, networking e disseminação dos resultados. No entanto, a pandemia impossibilitou este cenário. Desta forma, a disseminação dos resultados ocorreu por meio do site e instagram da Ativa Incubadora e também por meio da escrita deste artigo que será divulgado entre os pares e os ambientes de empreendedorismo e inovação. Além disso, apesar dos desafios para o mundo virtual necessários em relação a proposta inicial, que situava-se em ambiência presencial, o projeto pôde ser executado com êxito.

Como sugestões de trabalhos futuros, desenvolver uma análise da evolução destes empreendimentos e um comparativo do antes de depois, do quanto este trabalho com suas capacitações, consultorias e mentorias refletirão nos processos a longo prazo.

\section{Referências}

Ativa Incubadora do IFMT. (2020). Orientação No 02/2020 - Orientações para Incubação na Ativa em 2020. OFÍCIO No 30/2020 - RTR-PROEX/RTR/IFMT. Bernardi, L. A. (2012). Manual de empreendedorismo e gestão. (2a ed.), Atlas.

Canaltech. (2019). Por que a maioria das pequenas empresas fecha as portas em menos de um ano? https://www.negociosdigitaisnapratica.com.br/microempresas-desaparecem-1o-ano/.

Cerne. (2019). Conceito. https://anprotec.org.br/cerne/menu/o-cerne/conceito/.

Chiavenato, I. (2015). Administração Geral e Pública. (4a ed.), Editora Manole.

Chiavenato, I. (2016). Desempenho Humano nas Empresas. (7a ed.), Ed. Atual.

Costa Júnior, J. F. da et al. (2021). A Matriz SWOT e suas subdimensões: uma proposta de inovação conceitual. Research, Society and Development. 10 (10), $1-14$.

Cope, J. (2003). Entrepreneurial learning and critical reflection discontinuous events as triggers for 'higher- level' learning. Management Learning. 34(4), 429450 .

Dornelas, J. (2015). Empreendedorismo na prática: mitos e verdades do empreendedor de sucesso. (3a ed.), Ed. LTC.

Dornelas, J. (2016). Empreendedorismo: transformando ideias em negócios. (6a ed.), Atlas.

Estival, K. G. S. et al. (2021). Educação empreendedora e negócios de impactos sociais: um estudo sobre o curso de Administração da Universidade Estadual de Santa Cruz, em Ilhéus, Bahia. Research, Society and Development. 10 (1), 1-10.

Exame. (2019). Um terço dos negócios no Brasil fecha em dois anos. https://exame.com/pme/um-terco-dos-negocios-no-brasil-fecha-em-dois-anos/.

Helms, M. M., \& Nixon, J. (2010). Exploring SWOT analysis -where are we now? Journal of Strategy and Management. 3 (3) $215-5110$.

IFMT - Instituto Federal de Mato Grosso. (2019). Empreender: Guia para Estudantes Montarem seu Negócio. Coordenação: Léa Paula V. X. C. De Morais. Cuiabá: IFMT.

Krugër, C., Burger, R. E. \& Minello, I. F. (2019). O papel moderador da educação empreendedora diante da intenção empreendedora. Revista Economia e Gestão. 19 (52). http://200.229.32.55/index.php/economiaegestao/article/view/18224/14852.

Mendes, J. (2015). Manual do empreendedor: como construir um empreendimento de sucesso. (2a ed.).

Negócios Digitais na Prática. (2019). Porque $80 \%$ das micro e pequenas empresas desaparecem no 1o ano? https://canaltech.com.br/gestao/por-que-a-maioriadas-pequenas-empresas-fecha-as-portas-em-menos-de-um-ano-41841/.

Pinto Júnior, J. S., Silvestro, A. R., Schirmer, C. M. E. S., \& Mueller, E. R. Training versus vulnerabilities: contributions of entrepreneurial education promoted by the Active Incubator of IFMT Companies. Research, Society and Development, 10, e188101119591. 10.33448/rsd-v10i11.19591. https://rsdjournal.org/index.php/rsd/article/view/19591.

Rede Jornal Contábil. (2019). 1 a cada 4 empresas fecha antes de completar 2 anos no mercado, segundo estudo do Sebrae. https://www.jornalcontabil.com.br/1 a-cada-4-empresas-fecha-antes-de-completar-2-anos-no-mercado-segundo-estudo-do-sebrae.

Torres, J. (2014). Guia da Startup. Editora Casa do Código. 